\title{
Pelatihan Menulis Teks Narasi Menggunakan Cartoon Story Maker di SMA Negeri Cilimus Kuningan
}

\author{
Dwiniasih, Wendi Kusriandi*, Andi Sutisno, Neneng Aminah \\ Fakultas Keguruan dan Ilmu Pendidikan, Universitas Swadaya Gunung Jati, Cirebon, Indonesia \\ *Coresponding Author: wendikusriandi@gmail.com \\ Dikirim: 12-06-2021 ; Direvisi: 14-06-2021 ; Diterima: 14-06-2021
}

\begin{abstract}
Abstrak: Guru merupakan pengelola dalam proses pengajaran, dan dalam pengelolaannya mereka dituntut kreatif dalam membangun proses pembelajaran yang menarik dan tercapai tujuan pembelajarannya. Dari hasil wawancara dan survei, ternyata masih banyak guru yang belum bisa untuk memanfaatkan fitur-fitur maupun aplikasi sebagai penunjang dalam pembelajaran daring. Hal ini akan menyulitkan pada rancangan proses kegiatan pembelajaran menulis yang dibuat yang meliputi materi, proses ajar, dan evaluasi. Keadaan ini akan membuat guru hanya terpaku pada buku ajar dan cara mengajar luring. Solusi dari permasalahan yang akan ditangani dalam kegiatan PKM ini adalah memberikan pelatihan menulis teks narasi menggunakan media cartoon story maker bagi guru dan siswa di SMA Negeri Cilimus Kabupaten Kuningan. Mitra pada kegiatan Program Kemitraan Masyarakat (PKM) yang diusulkan ini adalah guru dan siswa di SMA Negeri Cilimus Kabupaten Kuningan. Dengan kegiatan ini diharapkan dapat meningkatkan kemampuan guru dan siswa dalam pelajaran Bahasa Inggris dan Bahasa Indonesia SMA Negeri Cilimus Kabupaten Kuningan merancang proses kegiatan KBM untuk peningkatan kemampuan menulis teks narasi.
\end{abstract}

\section{Kata Kunci: Teks Narasi; Cartoon Story Maker}

Abstract: Teachers are managers in the teaching process, and in their management they are required to be creative in building interesting learning processes and achieving learning objectives. From the results of interviews and surveys, it turns out that there are still many teachers who have not been able to take advantage of features and applications to support online learning. This will make it difficult to design the process of writing learning activities that are made which include materials, teaching processes, and evaluations. This situation will make teachers only fixated on textbooks and offline teaching methods. The solution to the problems that will be handled in this PKM activity is to provide training in writing narrative texts using cartoon story maker media for teachers and students at SMA Negeri Cilimus, Kuningan Regency. Partners in the proposed Community Partnership Program (PKM) are teachers and students at SMA Negeri Cilimus, Kuningan Regency. This activity is expected to improve the ability of teachers and students in English and Indonesian lessons at SMA Negeri Cilimus, Kuningan Regency, to design the process of teaching and learning activities to improve the ability to write narrative texts.

Keywords: Narrative Text; Cartoon Story Maker

\section{PENDAHULUAN}

Seiring dengan perkembangan ilmu pengetahuan dan teknologi (IPTEK), penggunaan teknologi pada pembelajaran Bahasa Inggris dan Bahasa Indonesia di sekolah menjadi salah satu pilihan untuk menyampaikan materi yang sulit menjadi lebih mudah. Salah satu jenis penggunaan teknologi dalam pembelajaran yaitu komputer. Komputer memiliki peran yang sangat penting sebagai alat bantu dalam 
pembelajaran Bahasa Inggris dan Bahasa Indonesia. Komputer adalah alat pembelajaran, artinya dalam pembelajaran guru dapat memanfaatkan komputer secara optimal untuk memberikan fasilitas belajar siswa. Dalam penggunaan komputer dalam pembelajaran Bahasa inggris dan Bahasa Indonesia yang perlu diperhatikan dalam mencapai kesuksesan pembelajaran ini tergantung pada model pengajaran dan kebutuhan siswa.

Komputer sebagai media pembelajaran memiliki keunggulan-keunggulan dalam presentasi grafik dengan tampilan yang menarik, yang dapat dimanipulasi secara leluasa dalam bentuk representasi visual model Bahasa Inggris. Bloom dan Fletcher (Kusumah, 2010) mengemukakan bahwa grafik resolusi tinggi dan animasi memiliki potensi yang amat besar untuk diaplikasikan dalam pembelajaran. Cilimusapa kelebihan pada komputer sangat tepat digunakan dalam pembelajaran Bahasa Inggris dan Bahasa Indonesia.

Salah satu jenis media yang tepat dalam proses pembelajaran Bahasa Inggris dan Bahasa Indonesia yaitu software Cartoon Story Maker. Perangkat lunak dinamis merupakan media yang dapat memberikan kesempatan pada siswa untuk meningkatkan kemampuan dalam bahasa Inggris dan Bahasa Indonesia.

Media pembelajaran yang memberikan kesempatan pada siswa untuk memanipulasi objek, dapat meningkatkan pemahaman siswa. Hal ini sesuai dengan yang dikemukan oleh Piaget (Suparno, 1997) yang menyatakan bahwa pengetahuan dibentuk seseorang melalui interaksi dengan pengalaman terhadap objek. Hal ini sejalan dengan Suharta (2001) yang menyatakan bahwa penting mengaitkan pengalaman kehidupan nyata anak dengan ide-ide Bahasa inggris dan Bahasa Indonesia dalam pembelajaran di kelas agar siswa belajar dengan bermakna.

Santos-Trigo (Awe, 2007) menemukan bahwa peran perangkat lunak dinamis menjadi alat penting untuk membimbing siswa mengeksplorasi hubungan Bahasa inggris dan Bahasa Indonesia. Salah satu perangkat lunak dinamis yang digunakan dalam pembelajaran Bahasa Inggris dan Bahasa Indonesia adalah Cartoon Story Maker. Cartoon Story Maker merupakan salah satu software Bahasa inggris yang dinamis memuat kajian Bahasa Inggris dan Bahasa Indonesia. Penggabungan antara perintah-perintah menulis dan membaca dan menjadikan Cartoon Story Maker sebagai media pilihan dalam menyampaikan konsep belajar Bahasa Inggris dan Bahasa Indonesia di sekolah.

Dalam pembelajaran Bahasa Inggris dan Bahasa Indonesia, terkadang merupakan kendala berat bagi siswa memahami dan meningkatkan kemampuan. Oleh karena itu, penggunaan Cartoon Story Maker diharapkan dapat memotivasi siswa agar lebih tertarik belajar Bahasa inggris dan Bahasa Indonesia dan lebih mudah dalam memahami konsep Bahasa inggris dan Bahasa Indonesia.

Berdasarkan analisis situasi dan kajian pustaka di atas, dapat disimpulkan bahwa para guru dan siswa SMA Negeri Cilimus Kabupaten Kuningan belum bisa mengoptimalkan pemanfaatan media komputer sebagai salah satu alat pembelajaran. Permasalahan tersebut disebabkan oleh berbagai faktor, satu diantaranya yang sangat penting adalah pengetahuan dan kemampuan penguasaan software Bahasa Inggris sehingga diperlukan pengetahuan tambahan.

Dengan demikian, dapat dirumuskan permasalahan para guru dan siswa SMA Negeri Cilimus Kabupaten Kuningan dalam optimalisasi pemanfaatan media

@ 2021 JagoMipa (https://bimaberilmu.com/jurnal/index.php/jagomipa) 
komputer. Adapun kegiatan ini difokuskan pada pemanfaatan software Cartoon Story Maker. Secara lebih operasional sebagai berikut.

1. Bagaimana memotivasi (membangun kemauan) diri siswa untuk menggunakan dan memanfaatkan software Cartoon Story Maker?

2. Bagaimana meningkatkan pemahaman dan ketrampilan siswa dalam pemanfaatan software Bahasa Inggris dan Bahasa Indonesia dalam hal ini software Cartoon Story Maker?

Berdasarkan permasalahan di atas, maka tujuan umum penulisan ini adalah untuk mengetahui penggunaan Software Cartoon Story Maker dalam pembelajaran Bahasa Inggris dan Bahasa Indonesia di sekolah.

\section{METODE PELAKSANAAN KEGIATAN}

Untuk melaksanakan kegiatan tersebut digunakan beberapa metode pelatihan sebagai berikut.

\section{Metode Ceramah}

Metode ceramah dipilih untuk memberikan penjelasan tentang software Cartoon Story Maker memotivasi siswa agar mau menggunakan dan memanfaatkan software Cartoon Story Maker dalam minat membaca, cara memanfaatkan software Cartoon Story Maker dalam pembelajaran Bahasa inggris dan Bahasa Indonesia dan sangat penting untuk dikuasai oleh peserta pelatihan.

\section{Metode Tanya Jawab}

Metode tanya jawab sangat penting bagi para peserta pelatihan, baik di saat menerima penjelasan tentang cara penggunaan software Cartoon Story Maker serta saat mempraktekkannya, Metode ini memungkinkan siswa menggali pengetahuan sebanyak-banyaknya tentang penggunaan dan pemanfaatan Cartoon Story Maker dan juga pengalaman setelah praktek menggunakan software Cartoon Story Maker.

\section{Metode Simulasi}

Metode simulasi ini sangat penting diberikan kepada para peserta pelatihan untuk memberikan kesempatan mempraktekan materi pelatihan yang diperoleh. Harapannya, peserta pelatihan akan benar-benar menguasai materi pelatihan yang diterima, mengetahui tingkat kemampuannya menerapkan kegiatan penggunaan software Cartoon Story Maker secara tehnis dan kemudian mengidentifikasi kesulitan-kesulitan (jika masih ada) untuk kemudian dipecahkan.

\section{IMPLEMENTASI KEGIATAN DAN PEMBAHASAN}

Pelaksanaan dilakukan pada tanggal 8 Maret 2021, Metode kegiatan ini berupa pelatihan kepada para guru dan siswa SMA N 1 Cilimus Kabupaten Cirebon. Setelah diberi pelatihan, selanjutnya mereka dibimbing untuk menerapkan hasil pelatihan dalam rangka meningkatkan hasil belajar dalam kegiatan teknis penggunaan dan pemanfaatan software Cartoon Story Maker dalam pembelajaran Bahasa Inggris.

Pada saat pelaksanaan pelatihan ada beberapa tahapan yang dilakukan. Pertama, penjelasan tentang pentingnya penggunaan software dalam pembelajaran Bahasa Inggris yaitu software Cartoon Story Maker, sesi pelatihan ini menitikberatkan pada pemberian penjelasan mengenai pentingnya penggunaan teknologi dalam pembelajaran Bahasa Inggris untuk memotivasi guru dan siswa agar mau menggunakan dan memanfaatkan software Cartoon Story Maker mengerjakan 
soal soal reading. Kedua, sesi pelatihan yang menitikberatkan pada kemampuan melaksanakan kegiatan tentang (1) melakukan instalasi Cartoon Story Maker (2) mengeksplorasi dan menggunakan menu dan tool Cartoon Story Maker untuk mengkonstruksi objek Bahasa Inggris, (3) mendesain aktivitas untuk pengintegrasian Cartoon Story Maker dalam pembelajaran Bahasa Inggris. Pemberian kemampuan ini dilakukan dengan teknik simulasi agar para guru dan siswa mendapatkan pengalaman langsung sekaligus pengayaan dari teman-temannya dan tim pelatih. berikut:

Berikut ditunjukkan cara pemakaian Cartoon Story Maker adalah sebagi

- Pertama-tama kita harus meng-ekstraknya terbih dahulu. Setelah selesai, klik dua kali pada software Cartoon Maker >> Next

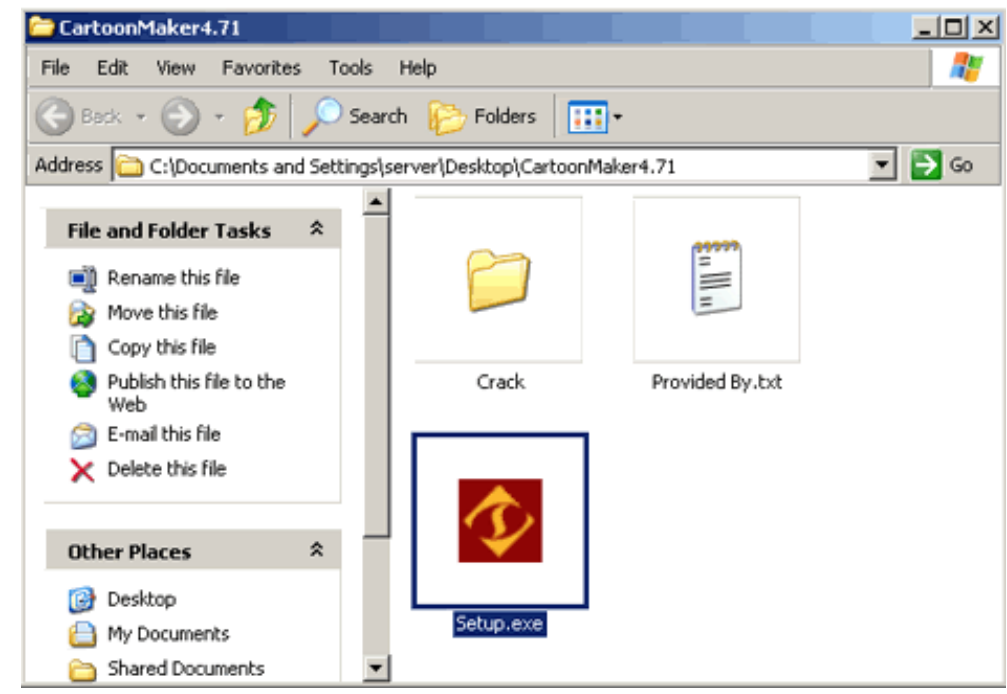

- Pada tulisan "Welcome to the cartoon...." $>>$ Next

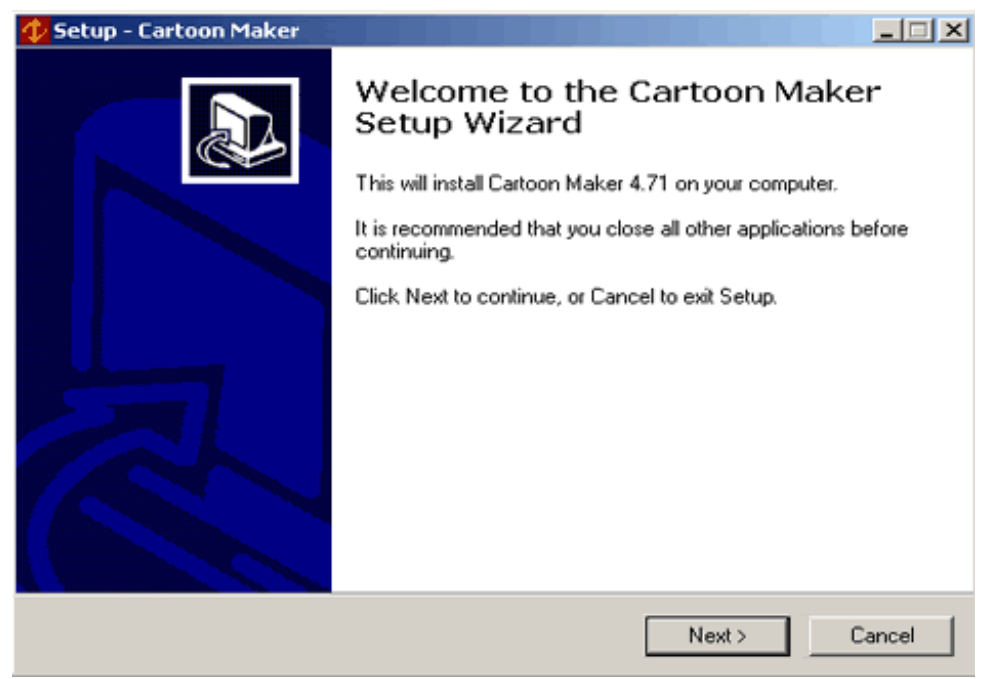

- Terdapat tulisan "Licence Agreement.." Pilih \& beri centang pada "I accept the agreement..." >> Next 


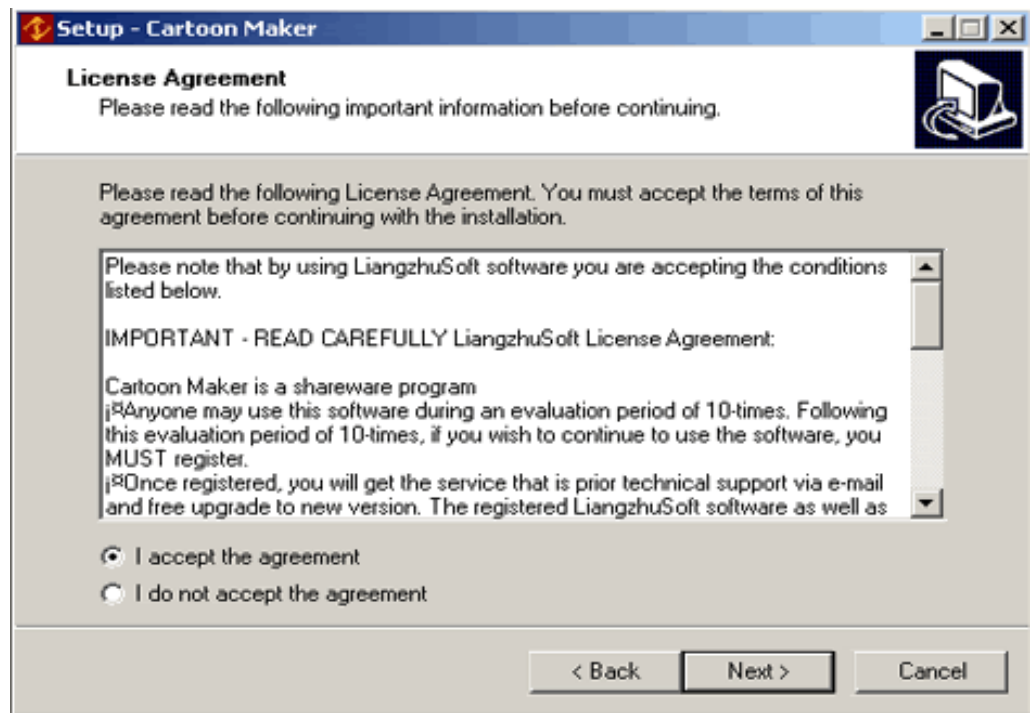

- Pada tulisan "Select Destination Location...." >> Next

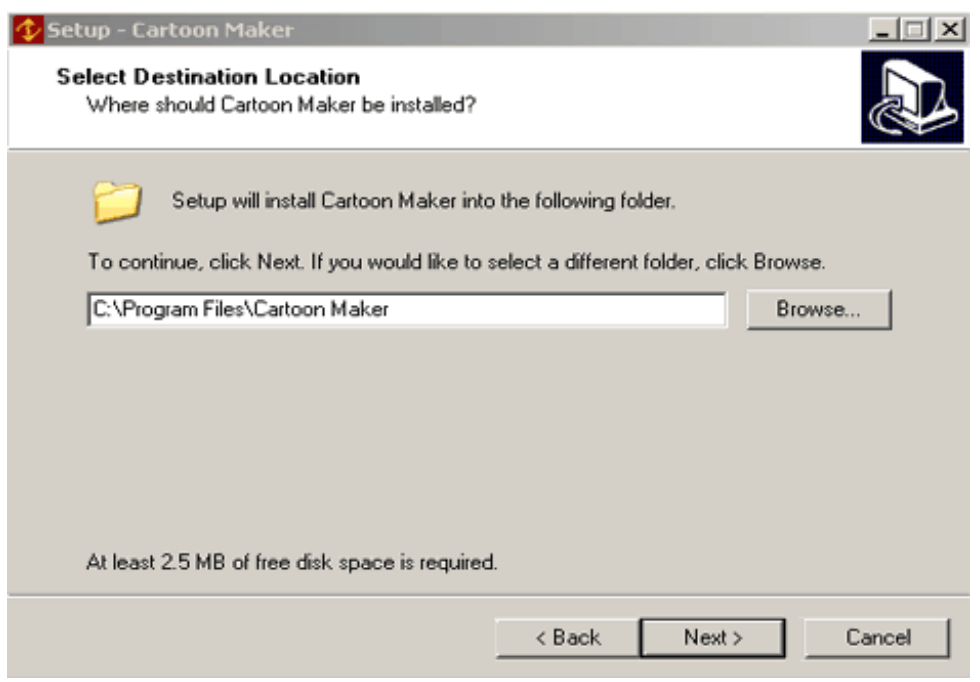

- Muncul tulisan "Select start menu...." >> Next

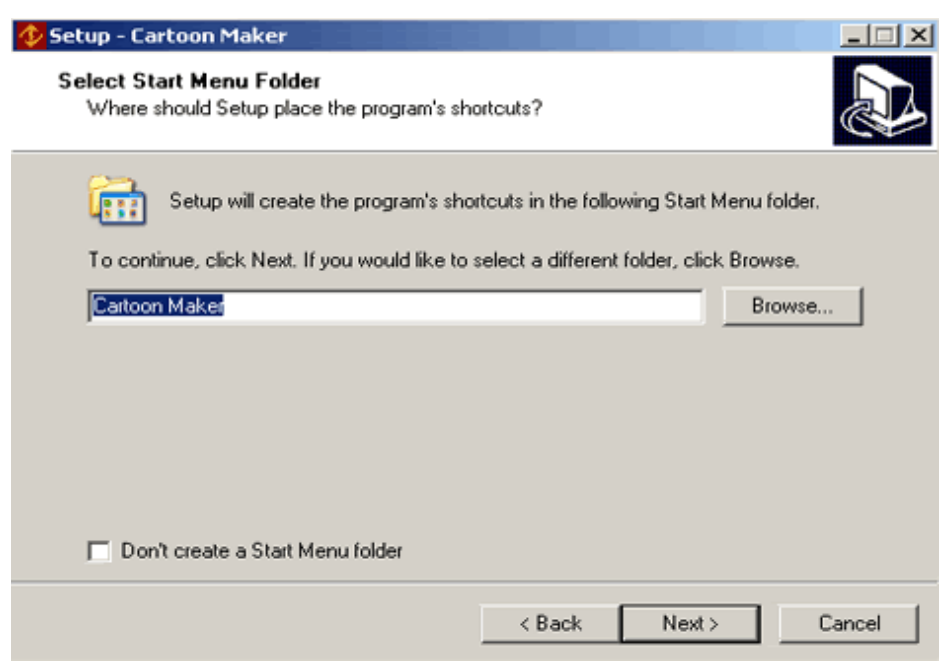

@ 2021 Bima Abdi (https://bimaberilmu.com/jurnal/index.php/bp-jpm) 
- Sebaliknya, jika anda menginginkan shortcut cartoon maker terdapat pada desktop dan quick lauch icon, beri centang pada kotak keduanya $\gg$ Next

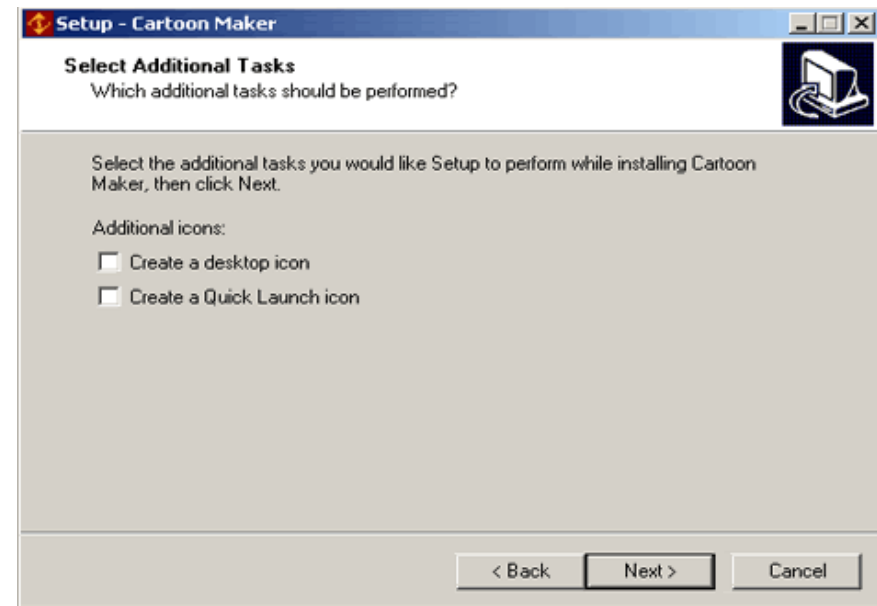

- "Ready to Install..." >> install

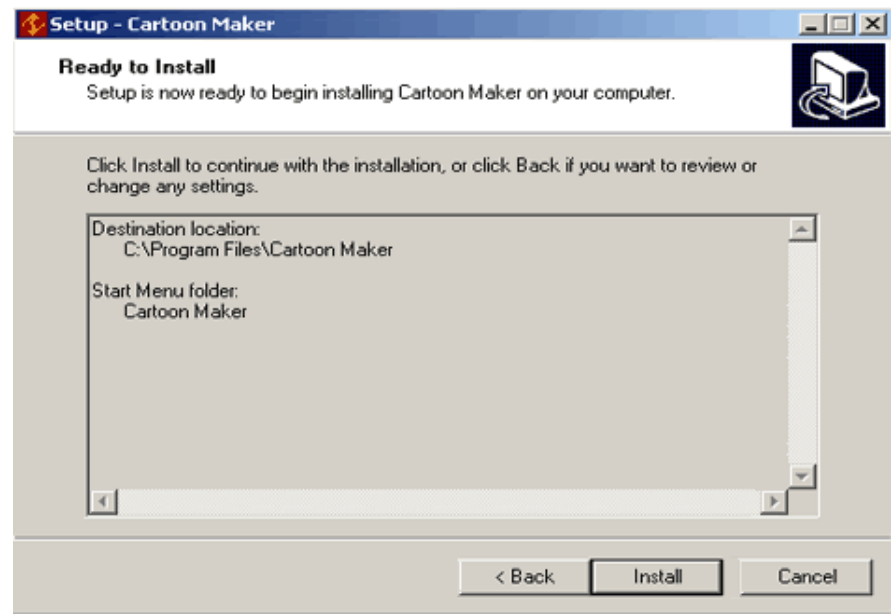

- Tunggu hingga proses instalasi selesai..

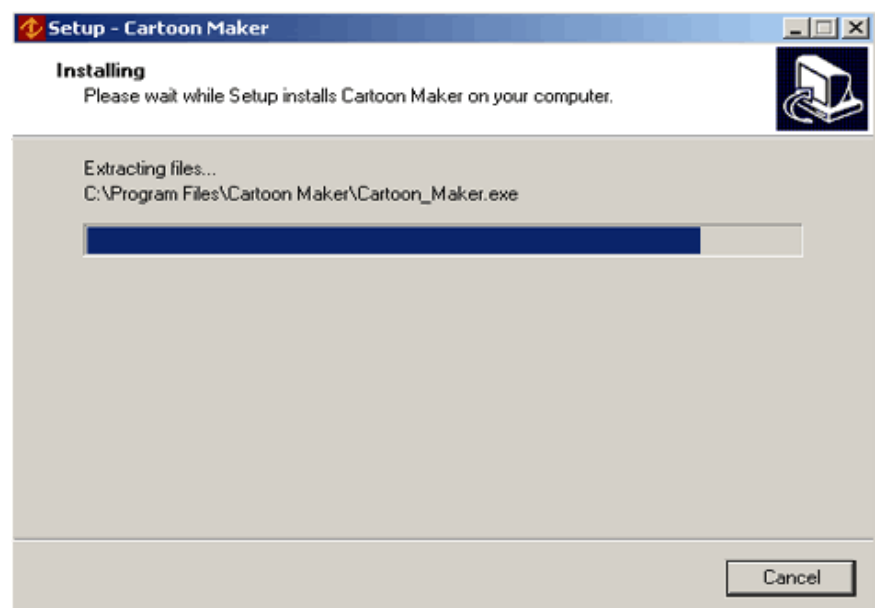

- Nah.. instalasi sudah selesai. Langsung >> Finish

@ 2021 JagoMipa (https://bimaberilmu.com/jurnal/index.php/jagomipa) 

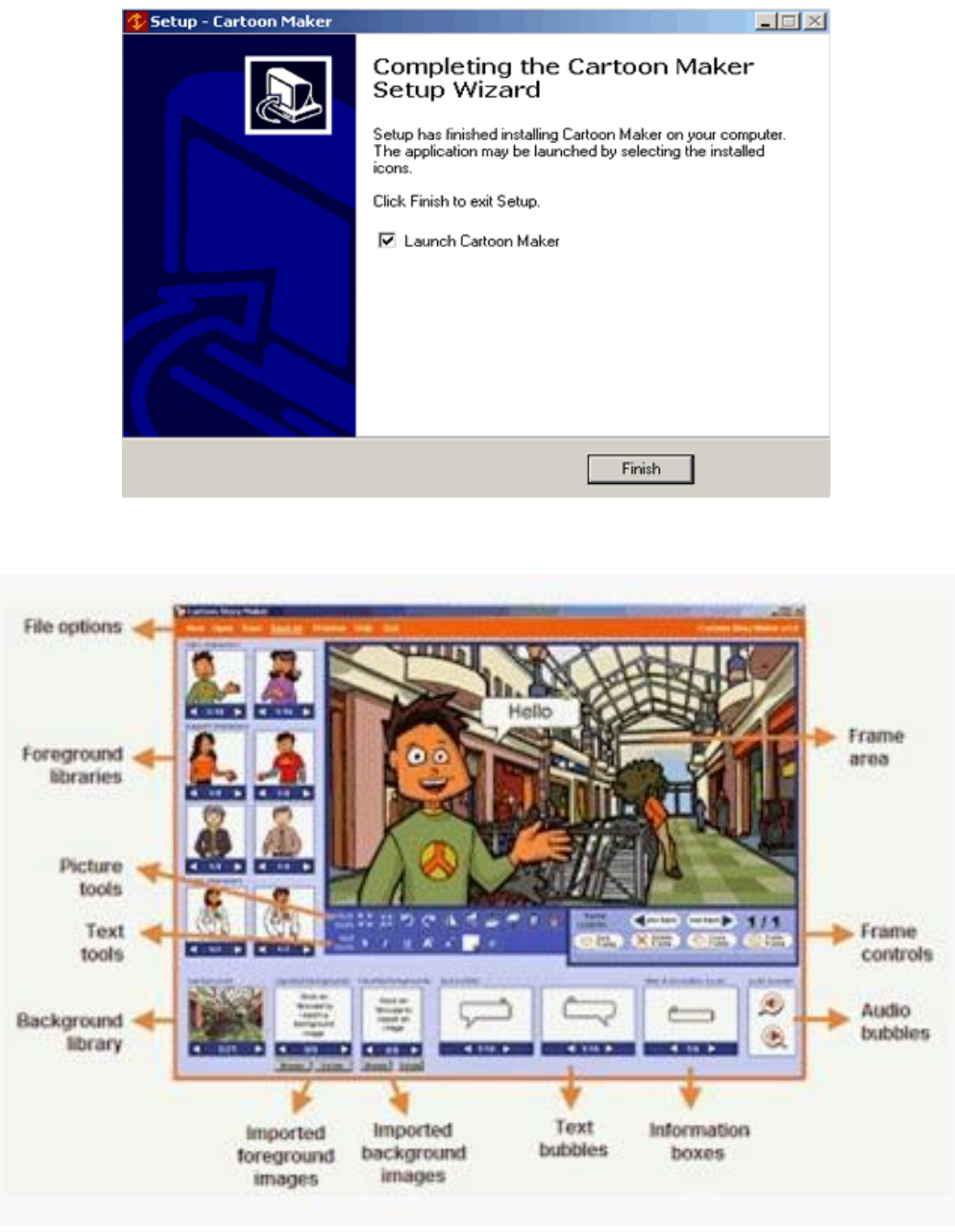

Berikut ini adalah link unduhan software dan tutorial yang dapat membantu teachers dalam menggunakan CSM sebagai media pembelajaran.

Tutorial http://www.4shared.com/office/6xzHu0KYce/CSM_help.html

Cartoon Story Maker http://cartoon-story-maker.software.informer.com/1.1/

Untuk cara mengunduh software, teachers tinggal klik Cartoon Story Maker. Lalu, akan muncul halaman baru dan klik tombol download seperti yang ditunjukan oleh gambar di bawah ini dan klik save. Setelah itu, cari unduhan CSM dan klik run maka CSM akan diinstal di computer teachers sekalian. Selamat Mencoba. 


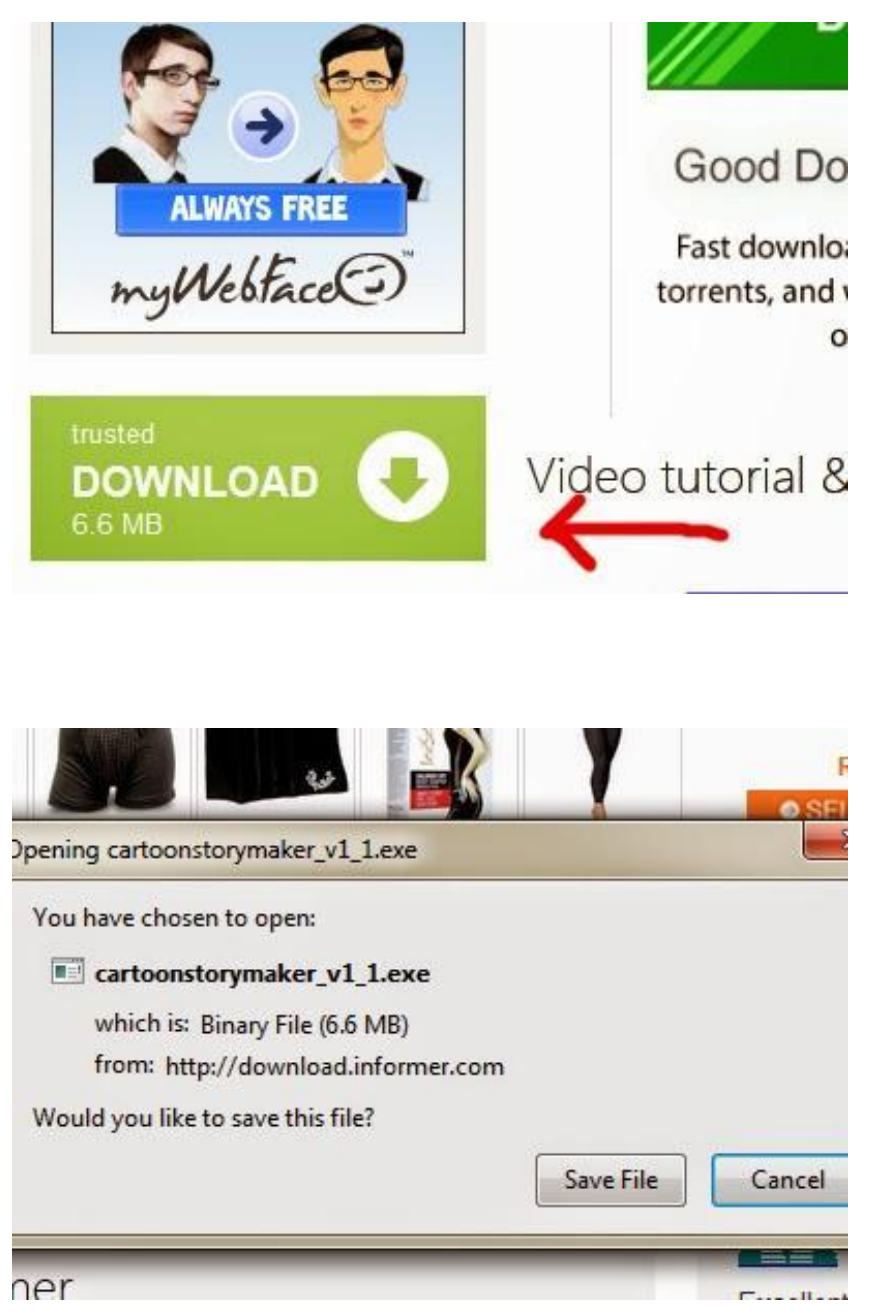

Indikator keberhasilan pelatihan ini adalah:

1) Lebih dari $80 \%$ peserta memahami kegiatan pelaksanaan pelatihan penggunaan dan pemanfaatan software Cartoon Story Maker dalam pembelajaran Bahasa inggris dan Bahasa Indonesia.

2) Lebih dari $75 \%$ peserta mampu mempratekkan yaitu penggunaan software Cartoon Story Maker.

3) Lebih dari $50 \%$ peserta bersedia mensosialisasikan kemampuan penggunaan software Cartoon Story Maker

Keberhasilan kegiatan pengabdian masyarakat ini akan dievaluasi berdasarkan taraf penyelesaian materi pelatihan, dan tim pengabdian akan melakukan evaluasi dengan mengamati dan memeriksa penerapan penggunaan dan pemanfaatan software Cartoon Story Maker dalam pembelajaran Bahasa Inggris oleh guru yang mengikuti pelatihan.

Instrumen kriteria penilaian tingkat kebermanfaatan kegiatan pelatihan ini diungkap dengan instrumen kuesioner. Menurut data yang didapat melalui kuesioner, software CSM ini sangat baik diaplikasikan dalam pembelajaran Bahasa Inggris yang dinilai mereka merupakan mata pelajaran yang menantang. Selain itu, Bahasa Inggris adalah mata pelajaran yang membosankan. Kelebihan dari software ini adalah 
aplikasinya yang bervariasi dan mudah digunakan sehingga memunculkan minat dan ketertaikan siswa dalam belajar.

Pelatihan tentang software cartoon story maker sangat bermanfaat bagi peserta. Hal tersebut tampak pada respons hasil angket yang menunjukan bahwa 95,6 persen peserta merasakan manfaat dengan bertambahnya pengetahuan tentang media pembelajaran cartoon story maker. Pengetahuan-pengetahuan yang dimaksud berkaitan dengan bagaimana cara instalasi software, menú-menu dan tolos yang ada dalam aplikasi, dan penggunaan tahap demi tahap software cartoon story maker.

Penerapan media ini dalam pembelajaran bahasa tentu menjadi alternatif lain bagi guru dalam melakukan inovasi pembelajaran. Dengan kata lain, media story cartoon maker memberikan alternatif media bagi guru bahasa ketika memberikan pembelajaran, khususnya materi teks narasi. Teks narasi akan lebih mudah disampaikan dengan media yang cocok atau sesuai. Media yang cocok atau sesuai dalam pembelajaran teks narasi yaitu cartoon story maker. Hal ini sesuai dengan hasil angket yang menyatakan bahwa 97,4 persen guru terbantu dengan media cartoon story maker dalam pemebelajaran teks narasi. Selain itu, penggunaan cartoon story maker dapat meningkatkan minat baca siswa dalam pemebalajaran bahasa. Hal ini sesuai dengan hasil angket yang menyatakan bahwa 96,2 persen minat baca siswa meningkat pada saat media cartoon story maker ini digunakan.

\section{KESIMPULAN}

Pelatihan penggunaan software timetable sangat bermanfaat bagi guru dan siswa pada sekolah tersebut, terutama dampak yang dihasilkan, guru yang mengikuti pelatihan sangat bersemangat untuk mempelajari.

Pengenalan software timetable sebaiknya tidak dilakukan hanya pada satu sekolah, tetapi terus diberikan kepada sekolah lainnya. karena dengan adanya pelatihan ini dapat menumbuhkan motivasi guru untuk bekerja secara lebih profesional dan mampu membuat pembelajaran lebih menarik dan menyenangkan dengan berbagai inovasi dalam pembelajaran.

\section{DAFTAR PUSTAKA}

Barbara Schmidt-Unterberger (2018) The English-medium paradigm: a conceptualisation of English-medium teaching in higher education International Journal of Bilingual Education and Bilingualism, Volume 21, 2018 - Issue 5. Published Online: 12 Jul 2018

Dogan, M \& Icel, R. (2009). The Role of Dynamic Geometry Software in the Process of Learning: Cartoon Story Maker Example About Triangles. Journal Department of Primary Mathematics Education. Konya: University of Selcuk.

Eva Domingue (2019). Teaching Media Literacy: Harnessing the Charm of Storytelling with NUSHU. Childhood Education Volume 95, 2019 - Issue 5 \begin{tabular}{l|llll} 
Pages & $44-48$ & Published online: & 16 & Sep
\end{tabular} https://doi.org/10.1080/00094056.2019.1663095

LeBlanc, C. (2017). Introduction to media studies. Licensed under a creative commons attribute 4.0 international license. Retrieved from August 3, 2020, from https://mediastudies. pressbooks.com 
Pavlik, J., \& McIntosh, S. (2018). Converging media: An introduction to mass communication (6th ed.). Oxford University Press.

Suparno, P. (1997). Filsafat Konstruktivisme dalam Pendidikan. Yogyakarta: Kanisus. 